The presence in the hepatic granulomas of eosinophils raised the possibility of Toxocara infestation. Larval remnants were not present within the granulomas nor was there peripheral eosinophilia or any other manifestation of larval migration-for example chorioretinitis. Although there are numerous causes of hepatic granulomas the liver in this case showed features previously reported in extensive Crohn's disease ${ }^{6}$-namely pericholangitis, inflammation of the portal tracts, and increased fibrosis.

How should we interpret the presence in our patient of virtual total villus atrophy? Two reports of the coexistance of Crohn's and coeliac diseases are extant ${ }^{78}$; each was associated with other evidence of classical Crohn's disease however, and upon withdrawal of dietary gluten there was clear histological evidence of mucosal recovery. In Crohn's disease per se, a variety of small-bowel mucosal abnormalities has been described. ${ }^{5}$ These are usually of a patchy nature and are most obvious adjacent to areas of frank mucosal ulceration. The case reported by Daum et al. ${ }^{3}$ was found initially to have mucosal changes suggestive of coeliac disease on jejunal biopsy but in comparison with our case, the abnormalities were not severe nor did symptoms remit after gluten withdrawal. Our patient requires further study to confirm persisting gluten sensitivity, nevertheless, it seems improbable that the abnormal jejunal histology is a manifestation of Crohn's disease per se.

\section{References}

1 Heaton K W, McCarthy C F, Horton R E, Cornes J S, Read A E. Miliary Crohn's disease. Gut 1967; 8: 4-7.

2 Manns J J. Miliary Crohn's disease. Br Med J 1972; ii: 152.

3 Daum F, Boley S J, Cohen M L. Miliary Crohn's disease. Gastroenterology 1974; 67: 527-30.

4 Bartnik W, Krynski J, Butruk E, Orlowski J. Miliary Crohn's disease. Br Med J 1977; i: 1135-6.

5 Nugent F W, Richmond M, Park S K. Crohn's disease of the duodenum. Gut 1977; 18: 115-20.

6 Eade M N, Cooke W T, Brooke B N, Thompson H. Liver disease in Crohn's colitis. Ann Intern Med 1971; 74: 518-28.

7 Anonymous. Clinicopathological conference: a case of Crohn's disease in a patient with treated adult coeliac disease. Br Med J 1967; iv: 222-6.

8 Eular A R, Ament M E. Celiac sprue and Crohn's disease: an association causing severe growth retardation. Gastroenterology 1977; 72: 729-31.

Correspondence to Dr J F T Glasgow, Department of Child Health, Institute of Clinical Science, Grosvenor Road, Belfast BT12 6BJ.

Received 27 August 1982

\title{
Laryngospasm as a single manifestation of epilepsy
}

\section{J AMIR, S ASHKENAZI, T SCHONFELD, R WEITZ, AND M NITZAN}

Department of Paediatrics and Paediatric Neurology Unit, Beilinson Medical Centr, Petah Tiqva, and Tel Aviv University Sackler School of Medicine, Israel

SUMMARY A 6-year-old girl had recurrent dyspnoeic attacks during sleep caused by laryngospasm. An abnormal electroencephalogram and an excellent response to carbamazepine suggests the possibility that the laryngospasm was a manifestation of epilepsy.

Breathing difficulties are not uncommon during seizure activity. In generalised tonic-clonic seizures the face may become cyanotic during the tonic phase if respiration is suspended, and then becomes jerky and stertorous in the clonic phase. On rare occasions, there is retraction of the tongue with respiratory distress. Prolonged apnoeic spells were also observed in association with other manifestations of epilepsy. ${ }^{12}$
A patient who presented with recurrent nocturnal laryngospasms as the only motor phenomenon of a convulsive disorder, is reported here.

\section{Case report}

A 6-year-old girl was referred to the hospital with a 3-week history of dyspnoeic attacks which occurred only during sleep. She was a bright, well-developed child of healthy, unrelated parents. Pregnancy and delivery had been uneventful. Her developmental milestones had been attained at the appropriate ages, and there was no family history of neurological disease.

Physical and neurological examination showed no abnormalities. The results of laboratory studies, including routine haematological, biochemical, and serological profiles were normal-for example 
glucose $4.51 \mathrm{mmol} / 1$, calcium $2.35 \mathrm{mmol} / 1$, and magnesium $0.90 \mathrm{mmol} / 1$ concentrations.

During her time in hospital repeated attacks of respiratory distress caused by laryngospasm were observed every night and sometimes also in the afternoon, 1-2 hours after the child fell asleep. The attacks were identical and each began with a short cough followed by an intensive inspiratory effort with severe air hunger, generally without stridor. The patient became cyanotic, looked dazed, and restless. The attacks lasted for 2-3 minutes, and were followed by sleep and complete amnesia.

The following studies also gave normal results: direct and indirect laryngoscopy just after an attack, electrocardiogram with continuous monitoring (Holter) even during the attack, cranial computerised tomography, and brain stem-evoked response audiometry. Gastro-oesophageal reflux was not demonstrated by oesophagogram. A waking and a sleep electroencephalogram (EEG) on admission showed no abnormalities, but continuous EEG monitoring during 8 hours of night sleep showed paroxysmal short bursts of high voltage $5 /$ second spikes and waves, predominantly in the right parietal region (Figure). The episode of laryngospasm occurred immediately after one of the electrical bursts before rapid eye movement sleep. No sleep apnoea was recorded.

Treatment with carbamazepine (Tegretol) in a daily dose of $400 \mathrm{mg}$, resulted in remission of the attacks within 3 days, which persisted for 6 months up to the time of this report.

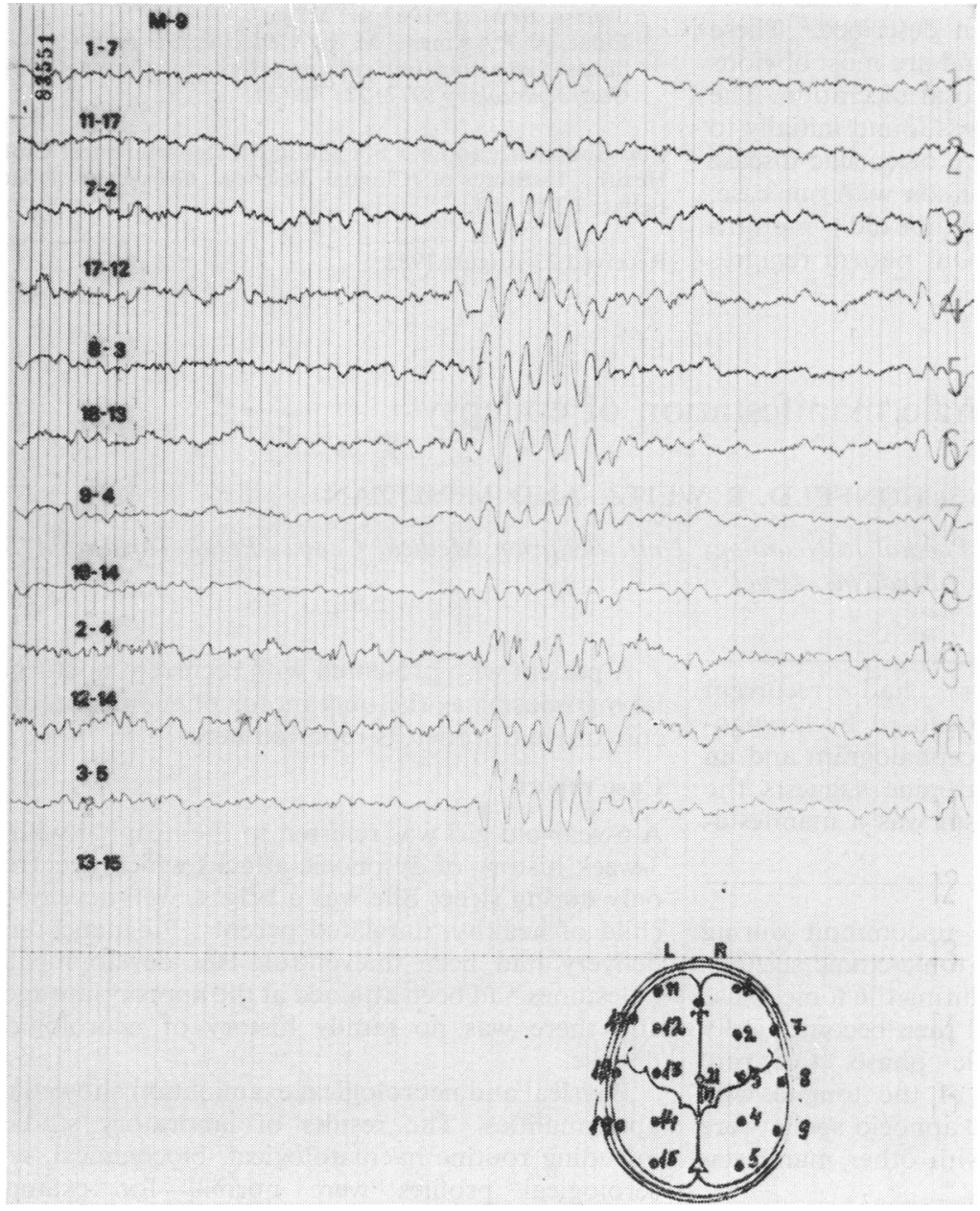

Figure Electroencephalogram during 8 hours of sleep. 


\section{Discussion}

Laryngospasm as a solitary manifestation of epilepsy is rare. It was reported in a girl who had a long history of repeated seizures. ${ }^{3}$ Nocturnal dyspnoeic attacks in children were described by Jackson and Jackson' ${ }^{4}$ and defined as 'sudden dyspnoeic seizures' but no electroencephalographic correlates were reported.

The usual causes of laryngospasm, hypocalcaemia, hypoparathyroidism, or hypomagnesaemia are encountered infrequently and can easily be ruled out. Laryngospasm during anaesthesia is fairly common. The reflex laryngospasm which may appear during light anaesthesia is somewhat similar to our case. Both occur during sleep and are initiated by a remote stimulus which most probably reaches the larynx via the superior laryngeal nerve. The high frequency of attacks in our patient enabled easy documentation of the EEG abnormalities during normal sleep. In view of our findings, we feel that an EEG should be done in selected cases of recurrent nocturnal laryngospasm, especially those associated with alteration of consciousness.
The prompt therapeutic response to carbamazepine both in our patient and in another ${ }^{3}$ supports the suggestion that this is an 'epileptic equivalent', and renders other therapeutic means unnecessary.

We thank Perez Lavi for performing the polygraphic sleep study.

\section{References}

1 Walls T J, Newman P K, Cumming W J K. Recurrent apnoeic attacks as a manifestation of epilepsy. Postgrad MedJ 1981 ; 57: 575-6.

2 Nelson D A, Ray C D. Respiratory arrest from seizure discharges in limbic system. Arch Neurol 1968; 19: 199-207.

3 Ravindran M. Temporal lobe seizure presenting as 'laryngospasm'. Clin Electroencephalogr 1981; 12: 129-30.

4 Jackson C, Jackson C L. Diseases of the nose, throat, and ear. Philadelphia: Saunders, 1945: 459.

Correspondence to Dr J Amir, Department of Paediatrics, Beilinson Medical Centre, Petah Tiqva 49 151, Israel.

Received 20 September 1982

\title{
Recurrent meningitis secondary to concealed cerebrospinal fluid otorrhoea
}

\author{
KEVIN P MANNING AND ROGER GUDRÜN \\ Department of Otorhinolaryngology, Walton Hospital, Liverpool
}

SUMMARY Three children who suffered recurrent attacks of meningitis which were eventually found to be due to a concealed cerebrospinal fluid otorrhoea are presented. Between them they had 12 attacks of meningitis before a firm diagnosis was made and treatment undertaken to localise and close the subarachnoid middle ear fistula.

Meningitis nowadays is associated with an overall mortality of $8 \%{ }^{1}$ Streptococcus pneumoniae is the organism generally associated with recurrent meningitis. From this the mortality rate varies from $13 \%$ in the UK and the Republic of Ireland ${ }^{1}$ to $51 \%$ in Nigeria. ${ }^{2}$ Complications-such as auditory and visual deterioration and hydrocephalus-are common and occur in $21 \%$ of cases. ${ }^{3}$ Every effort should be made to find the cause in any patient with recurrent meningitis.

\section{Case reports}

Case 1. A 15-year-old girl was seen with cerebrospinal fluid (CSF) rhinorrhoea. She had had rightsided blindness and ophthalmoplegia since a head injury at age 5 years. She had had meningism and an extradural abscess secondary to acute mastoiditis 4 years previously. Subsequently she had 2 attacks of meningitis preceded by CSF rhinorrhoea.

Otoscopic examination of the tympanic membrane showed a fluid level suggesting she had CSF otorrhoea. Exploration of the mastoid confirmed this. The fluid came from a defect in the roof of the mastoid, at the site of the previous extradural abscess. This was repaired from below with temporalis fascia and a free muscle graft.

Case 2. This 14-year-old boy had 5 attacks of pneumococcal meningitis. At age 8 years he had 